OPEN ACCESS

Edited by:

Ali Mentes,

Marmara University, Turkey

Reviewed by:

Sivakumar Nuvvula, Narayana Dental College and

Hospital, India

Deepti Shrivastava

Al Jouf University, Saudi Arabia

${ }^{*}$ Correspondence: David Drake

david-drake@uiowa.edu

Specialty section

This article was submitted to

Pediatric Dentistry,

a section of the journal

Frontiers in Dental Medicine

Received: 13 July 2021 Accepted: 03 September 2021 Published: 04 October 2021

Citation:

Villhauer A, Lynch D, Postler T,

Dawson D and Drake D (2021)

Mutans Streptococci and Lactobacilli: Colonization Patterns and Genotypic

Characterization of Cariogenic

Bacterial Species in American Indian

Children. Front. Dent. Med. 2:740900.

doi: 10.3389/fdmed.2021.740900

\section{Mutans Streptococci and Lactobacilli: Colonization Patterns and Genotypic Characterization of Cariogenic Bacterial Species in American Indian Children}

\author{
Alissa Villhauer ${ }^{1}$, David Lynch ${ }^{1}$, Taylor Postler ${ }^{1,2}$, Deborah Dawson ${ }^{1}$ and David Drake ${ }^{1 *}$ \\ ${ }^{1}$ lowa Institute for Oral Health Research, University of lowa College of Dentistry, lowa City, IA, United States, ${ }^{2}$ Primary Health \\ Care, Ames, IA, United States
}

Aim: The purpose of this study was to investigate the presence of Streptococcus mutans, Streptococcus sobrinus, and Lactobacillus species in an American Indian population displaying a high incidence of severe early childhood caries (S-ECC) and to explore the genotypic diversity and fidelity of transmission of S. sobrinus in this population.

Methods: We report here on the microbial profiles of 71 children compiled from birth to 36 months of age and initial exploration of genotypic diversity in a subset of 40 mother/child dyads. Whole mouth plaque samples were collected from mother/child dyads in a Northern Plains American Indian cohort. Mutans streptococci (MS) and Lactobacillus counts were recorded and presence/absence of S. mutans, S. sobrinus, and Lactobacillus was noted for each child. S. sobrinus was isolated and genotyped via arbitrarily primed-polymerase chain reaction (AP-PCR).

Results: The children in this study were divided into caries active (CA) and caries free (CF) groups. S. mutans, S. sobrinus, and Lactobacillus species were detected more frequently in CA groups. Distribution of MS and Lactobacillus counts was significantly different between the two groups, as was the distribution of three species colonization profiles. Twelve $S$. sobrinus genotypes were detected in the subset of mother/child dyads. Individual participants displayed a range of 0-3 distinct genotypes while mother/child pairs displayed a range of 1-5 genotypes. Eighty-three percent of children shared at least one genotype with his/her mother.

Conclusion: Caries active children in this population display different microbial profiles than the caries free children in this cohort. A small number of $S$. sobrinus genotypes appear to be very common in this population. A high rate of vertical transmission of $S$. sobrinus from mother to child is seen in these mother/child dyads.

Keywords: Streptococcus sobrinus, Streptococcus mutans, lactobacilli, severe early childhood caries, oral health disparities, genotyping, AP-PCR 


\section{INTRODUCTION}

Early childhood caries (ECC) remains a prevalent oral health challenge, despite efforts to establish successful preventive measures. A disproportionate amount of disease burden falls on low-income children and those from specific racial and ethnic groups. Among 2-5 year old children in the United States, the highest level of tooth decay is reported in American Indian and Alaska Native (AI/AN) children (1). Despite implementation of multiple preventive strategies that have been successful in other populations, very little progress has been made in decreasing the rate and severity of dental decay seen in this population (13). Previously published findings from the same cohort reported herein suggest that disease progression begins very early in these children. At 16 months of age, $61 \%$ present with precavitated or decayed, missing, or filled (dmf) lesions. By 36 months of age, the rate of children with cavitated lesions increased to $80 \%$ and non-cavitated lesions were reported in an additional $15 \%(4,5)$.

Many factors contribute to the onset and severity of decay. Social factors that have been associated with dental caries in AI/AN populations include maternal age, maternal education level, maternal DMFS, household income, household size, and caregiver perceptions about access to care and beliefs about oral health $(4,6)$. It is well-known that cariogenic bacteria also play a pivotal role in the development of ECC and its more aggressive form, severe early childhood caries (S-ECC). Among those most commonly researched due to their established role in the etiology and advancement of dental caries are the mutans streptococci (Streptococcus mutans and Streptococcus sobrinus) and lactobacilli. S. mutans has been linked to incidence and severity of dental caries in many populations (7-10). Recent studies of the oral microbiome have confirmed associations between S. mutans and other streptococcal species with caries and have highlighted the importance of understanding the microbial dysbiosis that influences the development and progression of dental caries (11-14).

We have conducted a 5-year longitudinal study of mother/child dyads $(n=239)$ from a Northern Plains American Indian Tribe (15). Following the children from birth to 36 months of age, the original focus was on initial acquisition of $S$. mutans, diversity and fidelity of transmission of S. mutans genotypes from mother to child, along with enumeration of $S$. mutans, lactobacilli, and total flora. After observing unexpectedly high levels of $S$. sobrinus in the population $(71 \%$ of research participants have S. sobrinus present), we expanded the scope of work to include isolation and genotypic analyses of both mutans streptococci (MS) species. We have previously reported on initial acquisition and genotypic diversity of $S$. mutans in this study population $(16,17)$. The focus of this manuscript is 2 -fold: (1) analyses of the presence of S. mutans, S. sobrinus, and lactobacilli in children from this cohort, including exploration of colonization patterns for the three bacterial species of interest; (2) genotypic diversity and fidelity of transmission of S. sobrinus in mother/child dyads.

\section{MATERIALS AND METHODS}

Descriptions of recruitment and consent practices, clinical examination protocols, sample collection and processing have been detailed previously $(5,16)$. The mutans streptococci isolation and identification procedure and AP-PCR protocols followed have also been described previously $(16,18)$. All procedures are summarized briefly here.

\section{Study Population, Recruitment, and Consent}

Mothers who were pregnant or who had just given birth were recruited from a Northern Plains American Indian Tribe $(n$ = 239). All onsite team members were AI, including a senior dental hygienist appointed as study director. Informed consent was obtained from all mothers who chose to participate in the study with their children. Approval for the study was sought and obtained from the Tribal Research Review Board, Aberdeen Area IRB, and University of Iowa IRB.

When this study began, a subset of 81 mother/child dyads was randomly selected for microbiological analyses. Of those 81, lactobacillus count data was unavailable for 10 , so those dyads were excluded from these analyses. Forty mother/child dyads were selected from the remaining 71 pairs for an initial exploration of S. sobrinus genotypic diversity. All children with $S$. sobrinus present at $\geq 2$ visits were included $(n=34)$. The remaining six pairs were randomly selected from the children with $S$. sobrinus detected at only one visit.

\section{Clinical Examination}

Trained and calibrated dental hygienist-examiners conducted caries examinations utilizing dmfs/DMFS (decayed, missing, and filled surfaces) criteria adapted from those used by NHANES (19). For the children, examiners employed the knee-to-knee

TABLE 1 | Presence/Absence of S. mutans, S. sobrinus, and lactobabillus species.

\begin{tabular}{lccccc}
\hline Bacterial species & & $\begin{array}{c}\text { Caries } \\
\text { active }\end{array}$ & $\begin{array}{c}\text { Caries } \\
\text { free }\end{array}$ & Total & P-value* \\
\hline S. mutans & Present & 52 & 13 & 65 & $p=0.0033^{*}$ \\
& & $98.11 \%$ & $72.22 \%$ & $91.55 \%$ & \\
& Absent & 1 & 5 & 6 & \\
S. sobrinus & & $1.89 \%$ & $27.78 \mathrm{~A} \%$ & $8.45 \%$ & \\
& Present & 43 & 7 & 50 & $p=0.0019^{*}$ \\
& & $81.13 \%$ & $38.89 \%$ & $70.42 \%$ & \\
& Absent & 10 & 11 & 21 & \\
& & $18.87 \%$ & $61.11 \%$ & $29.58 \%$ & \\
Lactobacilllus species & Present & 53 & 14 & 67 & $p=0.0031^{*}$ \\
& & $100 \%$ & $77.78 \%$ & $94.37 \%$ & \\
& & 0 & 4 & 4 &
\end{tabular}

*Significance probability ( $p$-value) associated with Fisher's exact test of no association between presence of the specified bacterial species and caries status. All results were significant at the 0.05 level. 
method to complete the examinations (20). In this study, children with a dmfs score of zero at their final examination (36 months of age) were classified as "Caries Free" and those with a dmfs score of $\geq 1$ were classified as "Caries Active."

\section{Sample Collection and Processing}

Whole mouth plaque samples were collected from AI mothers and babies at eight time points from birth to 36 months of age: Visit 1 (birth), V2 (4 months), V3 (8 months), V4 (12 months), V5 (16 months), V6 (22 months), V7 (29 months), and V8 (36 months). All visits occurred at the designated age \pm 30 days. Most visits were done in the participating family's home, but some were completed in the study's office on the Reservation. Originally, there were to be nine visits, all spaced 4 months apart, but due to the cost of shipping samples and the logistics of managing the number of visits and sample collections spread across the Reservation, one visit was eliminated and the final three visits were spread out (15). Samples were shipped to the laboratory in $0^{\circ} \mathrm{C}$ thermal packaging (Saf-T-Pak Inc., Hanover, MD, USA) via overnight FedEX delivery. Upon receipt, samples were diluted and spiral plated onto multiple media formulations for determination of total flora (Colombia blood agar base supplemented with sheep blood, hemin, and menadione), mutans streptococci (Mitis Salivarius Kanamycin Bacitracin agar), and Lactobacilli (Rogosa agar) counts.

\section{Mutans Streptococci Isolation and Identification}

Ten presumed MS colonies were isolated from MSKB agar at each time point. Isolates were identified as $S$. mutans or $S$. sobrinus following the established laboratory MS ID protocol preliminary identification by colony morphology on MSID plates and confirmation with PCR targeting the glucosyltransferase (gtf) genes of $S$. mutans (gtfB) and S. sobrinus (gtfI).

\section{Genotyping of S. sobrinus Isolates}

A rapid DNA extraction was performed $\left(95^{\circ} \mathrm{C}\right.$ for $15 \mathrm{~min}, 2 \mathrm{~min}$ vortex, centrifuge $10 \mathrm{~min}$ at $4^{\circ} \mathrm{C}$ at $10,000 \times \mathrm{g}$ ). Arbitrarily primed PCR (AP-PCR) was performed on $S$. sobrinus isolates using OPA-5 primer (5'-AGGGGTCTTG-3'). Streptococcus sobrinus ATCC 33478 was used as the positive control. DNA amplification was completed in a thermocycler (Eppendorf, Hauppauge, NY) with the following program settings: $5 \mathrm{~min}$ at $94^{\circ} \mathrm{C}$, followed by 45 cycles of $1 \mathrm{~min}$ at $94^{\circ} \mathrm{C}$ (denaturation), $2 \mathrm{~min}$ at $37^{\circ} \mathrm{C}$ (annealing), $2 \mathrm{~min}$ at $72^{\circ} \mathrm{C}$ (elongation), and finishing with $5 \mathrm{~min}$ at $72^{\circ} \mathrm{C}$. Number of genotypes present was determined by generation of dendrograms (Curve based cluster analysis using the Pearson correlation and unweighted pair group method using arithmetic averages) using GelCompar ${ }^{\circledR}$ II software (Applied Maths, Austin, TX, USA).

\section{Data Collection and Statistical Analyses}

Initial MS colonization data, presence/absence of the targeted bacterial species (S. mutans, S. sobrinus, lactobacilli), and three species colonization profiles were recorded for 71 children. $S$. sobrinus genotype profiles were generated for 40 children. Fidelity of transmission of $S$. sobrinus genotypes from mother to child was examined in 40 mother/child dyads.

The Wilcoxon-Mann-Whitney procedure was used to compare the distribution of species-specific microbial counts

TABLE 2 | Two-group comparison of distribution of Log transformed mutans streptococci and Lactobacillus counts by visit (base 10 logarithm of [CFU/ml +1]).

\begin{tabular}{|c|c|c|c|c|c|c|c|c|c|c|}
\hline & \multirow[b]{2}{*}{ Age (mo) } & \multicolumn{4}{|c|}{ Caries free } & \multicolumn{4}{|c|}{ Caries active } & \multirow[b]{2}{*}{$P$-value ${ }^{+}$} \\
\hline & & $N$ & $25 p c t l$ & Median & $75 p c t l$ & $N$ & 25 pctl & Median & 75pctl & \\
\hline \multirow[t]{8}{*}{ Mutans streptococci } & 1 & 17 & 0 & 0 & 0 & 52 & 0 & 0 & 0 & 0.7093 \\
\hline & 4 & 16 & 0 & 0 & 0 & 51 & 0 & 0 & 0 & 0.2068 \\
\hline & 8 & 18 & 0 & 0 & 0 & 50 & 0 & 0 & 0 & 0.2374 \\
\hline & 12 & 16 & 0 & 0 & 0 & 51 & 0 & 2.48 & 4.68 & $0.0014^{\star \star}$ \\
\hline & 16 & 17 & 0 & 0 & 1.61 & 51 & 2.66 & 4.64 & 5.43 & $<0.0001^{\star \star}$ \\
\hline & 22 & 18 & 0 & 0 & 3.15 & 52 & 3.05 & 4.59 & 5.7 & $0.0006^{\star \star}$ \\
\hline & 29 & 18 & 0 & 2.18 & 3.89 & 51 & 2.81 & 4.3 & 5.5 & $0.0032^{\star}$ \\
\hline & 36 & 18 & 1.32 & 2.9 & 5 & 51 & 3.46 & 4.78 & 5.51 & $0.0078^{*}$ \\
\hline \multirow[t]{8}{*}{ Lactobacillus species } & 1 & 17 & 0 & 1.32 & 3.66 & 52 & 0 & 2.98 & 3.99 & 0.2673 \\
\hline & 4 & 16 & 0 & 0 & 2.65 & 51 & 0 & 1.32 & 3.12 & 0.2535 \\
\hline & 8 & 18 & 0 & 0 & 0 & 50 & 0 & 0 & 2.94 & $0.0297^{\star}$ \\
\hline & 12 & 17 & 0 & 0 & 1.61 & 51 & 0 & 1.61 & 2.72 & 0.0967 \\
\hline & 16 & 15 & 0 & 0 & 0 & 51 & 0 & 2.08 & 3.51 & $0.0001^{* \star}$ \\
\hline & 22 & 18 & 0 & 0 & 0 & 50 & 0 & 2.08 & 3.03 & $0.0003^{\star \star}$ \\
\hline & 29 & 16 & 0 & 0 & 0 & 50 & 0 & 2 & 3 & $0.0011^{* *}$ \\
\hline & 36 & 18 & 0 & 0 & 0 & 49 & 0 & 1.61 & 2.58 & $0.0004^{\star *}$ \\
\hline
\end{tabular}

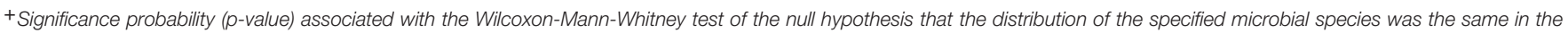
two groups defined by caries status.

${ }^{\star} P<0.05$. Results found to be significant at the 0.05 level before but not after adjustment for multiple comparisons; these may be regarded as suggestive results.

${ }^{\star}$ Results found to remain significant after adjustment for multiple comparisons using the Bonferroni method in conjunction with an overall 0.05 level of Type I error. 
TABLE 3 | Distribution of three species colonization profiles in caries free and caries active children.

\begin{tabular}{|c|c|c|c|c|c|c|c|}
\hline & \multicolumn{7}{|c|}{ Three species colonization profile* } \\
\hline Caries free & $16.67 \%$ & $38.89 \%$ & $11.11 \%$ & $16.67 \%$ & $11.11 \%$ & $5.56 \%$ & \\
\hline \multirow[t]{2}{*}{ Caries active } & 42 & 10 & 1 & 0 & 0 & 0 & 53 \\
\hline & $79.25 \%$ & $18.87 \%$ & $1.89 \%$ & $0.00 \%$ & $0.00 \%$ & $0.00 \%$ & \\
\hline
\end{tabular}

${ }^{*} p<0.0001$. Significance probability associated with Fisher's exact test assessing whether the distribution of colonization profiles differed between caries free and caries active groups. SM, Streptococcus mutans; SS, Streptococcus sobrinus; LB, Lactobacilli.

in children who remained caries free after 3 years of follow-up vs. those with active disease. Associations between caries status and either the presence of a particular bacterial species or the bacterial colonization pattern were assessed using the Fisher's exact test. The level of statistical significance was set at 0.05 . Adjustment for multiple comparisons was made using the Bonferroni method. Analyses were performed using SAS 9.4 (Cary, NC).

\section{RESULTS}

\section{Colonization of S. mutans, S. sobrinus, and Lactobacillus Species}

For every child, presence/absence of S. mutans, S. sobrinus, and lactobacillus species was determined (Table 1). Statistically significant differences were seen between the CA and CF groups for all three species ( $S$. mutans, $p=0.0033$; S. sobrinus, $p=$ 0.0019 , lactobacillus species, $p=0.0031$ ). Distribution of total mutans streptococci counts and total Lactobacillus counts were compared between $\mathrm{CA}$ and $\mathrm{CF}$ children at each time point samples were collected (Table 2). The distribution of mutans streptococci counts was significantly different for CA and CF children beginning at 12 months of age. Significant differences in distribution of lactobacillus counts between groups begin to be observed as early as 8 months of age.

A three species colonization profile was assigned to each child based on the presence/absence of S. mutans, S. sobrinus, and Lactobacilli in each child's plaque samples over the duration of the study. Six different three species colonization profiles were observed in these 71 children. Distribution of colonization profiles (Table 3 ) seen in CA children was different from that seen in CF children $(p<0.0001$, Fisher's exact test). Over $98 \%$ of CA children (52/53) exhibited one of two colonization profiles, SM+/SS+/LB+ and SM+/SS-/LB, while six different colonization profiles were observed in CF children. In no instance were all three species absent from the profile, nor did any child exhibit the SM+/SS+/LBcolonization profile.

\section{Genotypic Diversity and Fidelity of Transmission of S. sobrinus}

A total of 878 S. sobrinus isolates were analyzed via AP-PCR in 40 mother/child dyads. Twelve S. sobrinus genotypes were

\begin{tabular}{|c|c|c|c|c|c|}
\hline $\begin{array}{l}\text { S. sobrinus } \\
\text { genotype }\end{array}$ & Mothers & Children & $\begin{array}{c}\text { Total } \\
\text { participants }\end{array}$ & $\begin{array}{c}\% \text { of } \\
\text { isolates }\end{array}$ & $\begin{array}{l}\text { Number of } \\
\text { dyads with } \\
\text { transmission }\end{array}$ \\
\hline 1 & 19 & 18 & 37 & 29.16 & $\begin{array}{c}13 \\
32.50 \%\end{array}$ \\
\hline 2 & 1 & 0 & 1 & 0.11 & $\begin{array}{c}0 \\
0 \%\end{array}$ \\
\hline 3 & 15 & 19 & 34 & 34.28 & $\begin{array}{c}11 \\
27.50 \%\end{array}$ \\
\hline 4 & 1 & 0 & 1 & 0.34 & $\begin{array}{c}0 \\
0 \%\end{array}$ \\
\hline 5 & 1 & 2 & 3 & 1.94 & $\begin{array}{c}1 \\
2.50 \%\end{array}$ \\
\hline 6 & 18 & 19 & 37 & 28.82 & $\begin{array}{c}13 \\
32.50 \%\end{array}$ \\
\hline 7 & 0 & 2 & 2 & 0.23 & $\begin{array}{c}0 \\
0 \%\end{array}$ \\
\hline 8 & 3 & 3 & 6 & 2.73 & $\begin{array}{c}2 \\
5.00 \%\end{array}$ \\
\hline 9 & 0 & 1 & 1 & 1.14 & $\begin{array}{c}0 \\
0 \%\end{array}$ \\
\hline 10 & 0 & 1 & 1 & 0.57 & $\begin{array}{c}0 \\
0 \%\end{array}$ \\
\hline 11 & 0 & 1 & 1 & 0.57 & $\begin{array}{c}0 \\
0 \%\end{array}$ \\
\hline 12 & 1 & 0 & 1 & 0.11 & $\begin{array}{c}0 \\
0 \%\end{array}$ \\
\hline
\end{tabular}

detected (Table 4). Six (50\%) of these genotypes were observed in more than one participant. The most commonly detected genotypes were 1,3 , and 6 , which were isolated from 37 (46.3\%), 34 (42.5\%), and 37 (46.3\%) participants, respectively. These three genotypes accounted for over $90 \%$ of the S. sobrinus isolated from this subset.

Individual participants in this cohort displayed a range of $0-3$ S. sobrinus genotypes (Children: 1-3; Mothers: 0-3). A range of 1-5 genotypes was seen in Mother/Child dyads (Figure 1). As expected based on the genotypic diversity results, genotypes 1 , 3 , and 6 were most commonly shared between mother and child. Sixty-eight percent of children in this cohort (27/40) shared one genotype with his/her mother. Fifteen percent of dyads (6/40) 


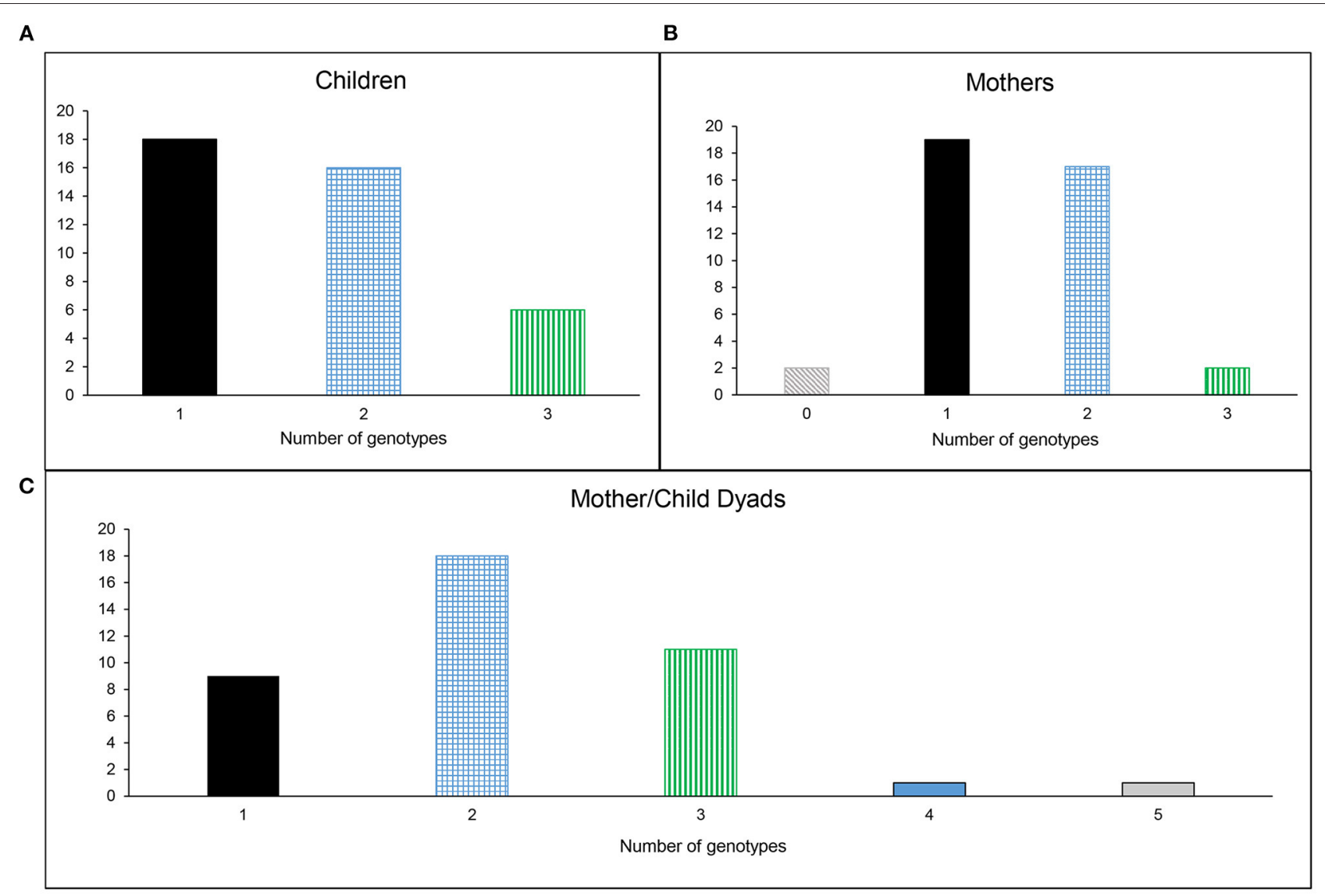

FIGURE 1 | Genotypic diversity of S. sobrinus in (A) Children, (B) Mothers, and (C) Mother/Child Dyads.

shared two genotypes. The remaining seven children did not share any S. sobrinus genotypes with their mothers (Figure 2).

\section{DISCUSSION}

This study monitored the presence of specific bacterial species associated with the onset and progression of dental caries during the first three years of life in American Indian children and their mothers. Levels of mutans streptococci and lactobacilli have been shown to correlate with the presence of S-ECC (21-23). In this study population, mutans streptococci (both $S$. mutans and $S$. sobrinus) were detected more frequently in children with caries than in children without caries. These findings are consistent with results reported from other populations $(8,24$, 25). Overall, S. mutans and S. sobrinus were present in 91.55 and $70.42 \%$ of children, respectively. Prevalence of S. mutans in other populations has been reported at rates as low as $23 \%$ and as high as $100 \%$ of participants while the range reported for $S$. sobrinus is $0-87 \%(24-32)$. While looking at combinations of oral streptococci observed in a cohort of Mexican children, MartinezMartinez et al. found that $100 \%$ of children with dmfs scores $>10$ had S. sobrinus present, while in those with a dmfs score of 1-5, S. sobrinus was only observed in $58.3 \%$ of participants (31). In the American Indian children, there was not as striking a difference based on dmfs score. In children with dmfs scores $\leq 9$ at the final visit, $72.7 \%$ had $S$. sobrinus present at $\geq 1$ visit. When $\mathrm{dmfs}$ score was $\geq 10,90.3 \%$ had $S$. sobrinus present at $\geq 1$ visit. This is not unexpected, as the prevalence of $S$. sobrinus across the population is high in this cohort (70.42\%), as stated previously.

Lactobacillus species were detected more frequently in CA children as they progressed through the study. Lactobacilli are secondary colonizers, establishing themselves in existing carious lesions (33-35), so it is not surprising to see a more consistent lactobacillus presence in the children with active caries. The percentage of children in this cohort with lactobacillus detected at $\geq 1$ visit was $94.37 \%$, which is toward the higher end of the range of $40-100 \%$ reported in other populations (36-40).

The earliest colonization of mutans streptococci in CF children was seen at the 12 month visit, while the earliest colonization in the CA group was observed at the baseline visit. While very early colonization of MS did occur in the CA group, this was not common. When looking at the distribution of MS counts in CA and CF children across all study visits, we did not detect a statistically significant difference in the distribution of total MS counts between groups until 12 months of age. Differences in the distribution of lactobacillus species counts was observed earlier than the MS counts. We observed significant 


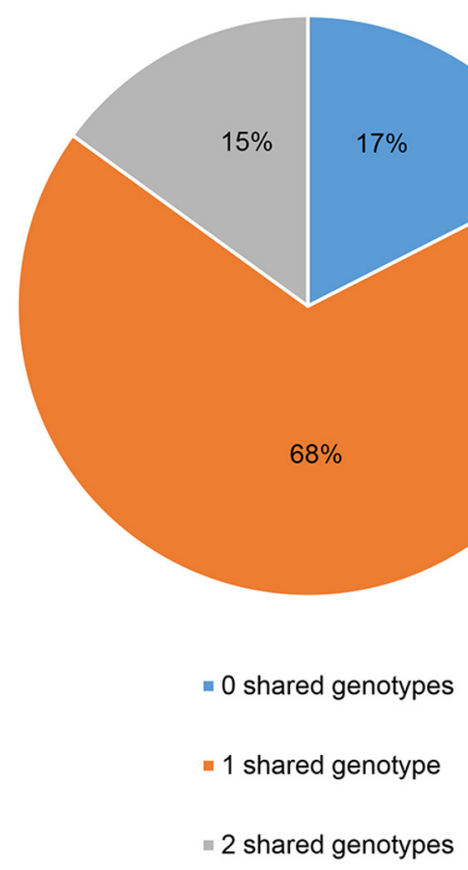

FIGURE 2 | Fidelity of transmission of S. sobrinus genotypes from mother to child.

differences in lactobacillus counts between the CA and CF groups by the time the children were 8 months of age.

The development of the oral microbiome in children is influenced by both maternal and environmental sources (11, 12). While other aspects of our overarching study have examined environmental influences that may play a role in the rampant caries observed in this population (4), the focus of microbiological reporting to date has been on genotypic diversity and maternal transmission of $S$. mutans $(16,17)$. Much research on the influence of the mutans streptococci on caries progression has indicated that the presence of $S$. mutans and $S$. sobrinus together results in greater disease risk than $S$. mutans alone $(8,24,27,41-43)$. Similarly, in this study, $16.67 \%$ of CF children had S. mutans and S. sobrinus, compared to $79.25 \%$ of CA children. It has been suggested that these two species may have a synergistic impact on disease progression (22, 25, 43). It is reasonable to postulate that the frequent occurrence of $S$. sobrinus and $S$. mutans together in this population may be a contributing factor to the severity of disease observed in these children.

With this cohort, we completed an initial analysis of $S$. sobrinus diversity and transimission. The few studies that have reported on genotypic diversity of $S$. sobrinus have observed between 8 and 23 genotypes within their target populations (4447). The findings in this population are within that range as well (12 S. sobrinus genotypes). When looking at genotypic diversity of $S$. mutans, we found that all participants analyzed shared at least one genotype with a participant from another mother/child dyad (data not shown). Similar to our findings with $S$. mutans in this population, there is a high rate of commonality of $S$. sobrinus genotypes as well. Half of the genotypes in this population are found in more than one participant. Ninety-six percent of participants $(48 / 50)$ shared $\geq 1$ genotype with a participant from another mother/child dyad. The remaining two participants were mothers that had no S. sobrinus present. Because three genotypes account for $90 \%$ of all S. sobrinus isolated from this population, it is not surprising to find that all participants with S. sobrinus colonization share at least one genotype with other participants from the cohort. For the same reason, it was not unexpected to observe that $83 \%$ of mother/child pairs shared $\geq 1$ genotype. This is very similar to the $S$. sobrinus transmission rate reported by Klein et al. (45). Overall, there appears to be a great deal of commonality in mutans streptococci genotypes among the population.

Johansson et al. report that long term dental care appears to impact the microbiota of a population over time. In a population with easy access to consistent care and preventive measures from early childhood, the role of mutans streptococci in caries was less pronounced than in a second population with limited access to care and treatment (48). This highlights the importance of access to consistent care and preventive treatments on oral health. Recent assessment of preventive strategies and interventions in American Indian populations show that preventive measures need to start early, be culturally appropriate, and may also need to target behaviors and beliefs of the parents $(2,49)$.

\section{STRENGTHS, LIMITATIONS, AND FUTURE DIRECTIONS}

We believe this to be a strong longitudinal study of a population displaying high levels of dental caries. Sound methods were used to complete the study. Interpretation of microbiological data was completed without bias and with statistical analyses appropriate to the available data. There were challenges and limitations at multiple points throughout this 5 year study. Challenges and logistics of the overall study have been detailed previously (15). For this portion of the study specifically, the biggest challenge was the imbalance of caries positive and caries negative children. As previously stated, $80 \%$ of the children had at least one cavitated lesion by 36 months of age. The percentage goes up to 95 percent when you add the children with uncavitated lesions. The disparity between caries free and caries active groups limited what could be determined as statistically significant differences between the groups.

In the future, we would like to further explore the microbiological components involved in the progression of SECC in this population by looking at the development of the complete oral microbiome in AI children, not just the mutans streptococci and lactobacillus species. It would also be valuable to compare the findings from this cohort to additional cohorts within other populations displaying high levels of oral health disparity in order to facilitate a better understanding of whether specific microbiological components contribute to why certain populations carry a disproportionate burden of oral decay. 


\section{CONCLUSIONS}

This population displayed a high incidence of dental caries in mothers and S-ECC in children. This study confirmed that $S$. mutans, S. sobrinus, and lactobacillus species play a role in the rampant caries observed in this population. Caries active and caries free children displayed different profiles of these bacterial species. Additionally, the rate of detection of Streptococcus sobrinus was much higher than anticipated and there was very little genotypic diversity of the S. sobrinus in these mother/child dyads, which could indicate a high rate of vertical and horizontal transmission of this species among this study population.

There is a definite need to address parental perceptions of barriers to oral health care and personal histories of poor oral health in working toward improved oral health for AI children. This, combined with a better understanding of the microbiological aspects of S-ECC in this population, may lead to innovative treatment approaches and new strategies to reduce the burden of S-ECC in AI children more successfully than the standard preventive measures that have been attempted to date.

\section{DATA AVAILABILITY STATEMENT}

The datasets presented in this article are not available and would need approval from the American Indian Tribe. Requests to access the datasets should be directed to david-drake@uiowa.edu.

\section{REFERENCES}

1. Phipps K, Ricks TL. The oral health of American Indian and Alaska native children aged 1-5 years: results of the 2014. IHS Oral Health Survey. Indian Health Service data brief (2015).

2. Albino J, Batliner TS, Tiwari T. Preventing caries in American Indian children: lost battle or new hope? JDR Clin Transl Res. (2017) 2:4069. doi: $10.1177 / 2380084417725690$

3. Ricks TL, Phipps KR, Bruerd B. The Indian health service early childhood caries collaborative: a five-year summary. Pediatr Dent. (2015) 37:275-80.

4. Warren JJ, Blanchette D, Dawson DV, Marshall TA, Phipps KR, Starr D, et al. Factors associated with dental caries in a group of American Indian children at age 36 months. Community Dent Oral Epidemiol. (2016) 44:15461. doi: $10.1111 /$ cdoe. 12200

5. Warren JJ, Kramer KW, Phipps K, Starr D, Dawson DV, Marshall T, et al. Dental caries in a cohort of very young American Indian children. J Public Health Dent. (2012) 72:265-8. doi: 10.1111/j.1752-7325.2012.00372.x

6. Tiwari T, Quissell DO, Henderson WG, Thomas JF, Bryant LL, Braun PA, et al. Factors associated with oral health status in American Indian children. J Racial Ethn Health Disparities. (2014) 1:148-56. doi: 10.1007/s40615-014-0017-3

7. Colombo NH, Kreling PF, Ribas LFF, Pereira JA, Kressirer CA, Klein MI, et al. Quantitative assessment of salivary oral bacteria according to the severity of dental caries in childhood. Arch Oral Biol. (2017) 83:2828. doi: 10.1016/j.archoralbio.2017.08.006

8. Fragkou S, Balasouli C, Tsuzukibashi O, Argyropoulou A, Menexes G, Kotsanos N, et al. Streptococcus mutans, Streptococcus sobrinus and Candida albicans in oral samples from caries-free and caries-active children. Eur Arch Paediatr Dent. (2016) 17:367-75. doi: 10.1007/s40368-0160239-7

9. Mattos-Graner RO, Klein MI, Smith DJ. Lessons learned from clinical studies: roles of mutans streptococci in the pathogenesis of dental caries. Curr Oral Health Rep. (2014) 1:70-8. doi: 10.1007/s40496-013-0008-1

\section{ETHICS STATEMENT}

Consent forms were obtained for all mothers who chose to participate in the study with their children. Approval was required from multiple agencies for this study: Tribal Research Review Board, Aberdeen Area IRB and University of Iowa IRB.

\section{AUTHOR CONTRIBUTIONS}

AV worked on processing samples, bacterial species enumeration, genotyping and dendrogram analyses of S. sobrinus isolates, data collection, and manuscript writing. DL worked on processing samples, bacterial species enumeration, and data collection. TP worked on genotyping and dendrogram analyses of $S$. sobrinus isolates and data collection. DDa contributed to this work by conducting statistical analyses of data sets, providing descriptions of analyses, and manuscript revisions. DDr was the primary investigator for this project and was involved in overseeing all aspects of the study, including study design, and manuscript revision. All authors contributed to the article and approved the submitted version.

\section{FUNDING}

This study was supported by NIH grant R01-DE017736.

10. Mitrakul K, Chanvitan S, Jeamset A, Vongsawan K. Quantitative analysis of S. mutans, Lactobacillus and Bifidobacterium found in initial and mature plaques in Thai children with early childhood caries. Eur Arch Paediatr Dent. (2017) 18:251-61. doi: 10.1007/s40368-017-0295-7

11. Dzidic M, Collado MC, Abrahamsson T, Artacho A, Stensson M, Jenmalm $\mathrm{MC}$, et al. Oral microbiome development during childhood: an ecological succession influenced by postnatal factors and associated with tooth decay. ISME J. (2018) 12:2292-306. doi: 10.1038/s41396-018-0204-z

12. Gomez A, Nelson KE. The oral microbiome of children: development, disease, and implications beyond oral health. Microb Ecol. (2017) 73:492503. doi: 10.1007/s00248-016-0854-1

13. Krishnan K, Chen T, Paster BJ. A practical guide to the oral microbiome and its relation to health and disease. Oral Dis. (2017) 23:276-86. doi: 10.1111/odi.12509

14. Xu H, Tian J, Hao W, Zhang Q, Zhou Q, Shi W, et al. Oral microbiome shifts from caries-free to caries-affected status in 3-yearold Chinese children: a longitudinal study. Front Microbiol. (2018) 9:2009. doi: $10.3389 /$ fmicb.2018.02009

15. Drake D, Dawson D, Kramer K, Schumacher A, Warren J, Marshall T, et al. Experiences with the Streptococcus Mutans in Lakota Sioux (SMILeS) Study: risk factors for Caries in American Indian Children 0-3 Years. J Health Dispar Res Pract. (2015) 8:123-32.

16. Lynch DJ, Villhauer AL, Warren JJ, Marshall TA, Dawson DV, Blanchette DR, et al. Genotypic characterization of initial acquisition of Streptococcus mutans in American Indian children. J Oral Microbiol. (2015) 7:27182. doi: 10.3402/jom.v7.27182

17. Villhauer AL, Lynch DJ, Warren JJ, Dawson DV, Blanchette DR, Drake DR. Genotypic characterization and comparison of Streptococcus mutans in American Indian and Southeast Iowa children. Clin Exp Dent Res. (2017) 3:235-43. doi: $10.1002 /$ cre2.94

18. Villhauer AL, Lynch DJ, Drake DR. Improved method for rapid and accurate isolation and identification of Streptococcus mutans and Streptococcus 
sobrinus from human plaque samples. J Microbiol Methods. (2017) 139:2059. doi: 10.1016/j.mimet.2017.06.009

19. Dye BA, Tan S, Smith V, Lewis BG, Barker LK, Thornton-Evans G, et al. Trends in oral health status: United States, 1988-1994 and 1999-2004. Vital Health Stat. (2007) 11:1-92.

20. Nowak AJ, Warren JJ. Infant oral health and oral habits. Pediatr Clin North Am. (2000) 47:1043-66. doi: 10.1016/S0031-3955(05)70257-1

21. Ramamurthy PH, Swamy HS, Bennete F, Rohini M, Nagarathnamma T. Relationship between severe-early childhood caries, salivary mutans streptococci, and lactobacilli in preschool children of low socioeconomic status in Bengaluru city. J Indian Soc Pedod Prev Dent. (2014) 32:447. doi: $10.4103 / 0970-4388.127054$

22. Mitrakul K, Akarapipatkul B, Thammachat P. Quantitative analysis of Streptococcus Mutans, Streptococcus Sobrinus and Streptococcus Sanguinis and their association with early childhood caries. J Clin Diagn Res. (2020) 14:ZC23-8. doi: 10.7860/JCDR/2020/43086.13513

23. Veena RL, Nagarathna C. Correlation of streptococcus mutans and streptococcus sobrinus colonization with and without caries experience in preschool children. Indian $J$ Dent Res. (2020) 31:73-9. doi: 10.4103/ijdr.IJDR_432_18

24. Jiang Q, Yu M, Min Z, Yi A, Chen D, Zhang Q. AP-PCR detection of Streptococcus mutans and Streptococcus sobrinus in caries-free and caries-active subjects. Mol Cell Biochem. (2012) 365:159-64. doi: 10.1007/s11010-012-1255-5

25. Saraithong P, Pattanaporn K, Chen Z, Khongkhunthian S, Laohapensang $\mathrm{P}$, Chhun N, et al. Streptococcus mutans and Streptococcus sobrinus colonization and caries experience in 3- and 5-year-old Thai children. Clin Oral Investig. (2015) 19:1955-64. doi: 10.1007/s00784-015-1437-0

26. Choi EJ, Lee SH, Kim YJ. Quantitative real-time polymerase chain reaction for Streptococcus mutans and Streptococcus sobrinus in dental plaque samples and its association with early childhood caries. Int J Paediatr Dent. (2009) 19:141-7. doi: 10.1111/j.1365-263X.2008.00942.x

27. Oda Y, Hayashi F, Wakita A, Nagatani Y, Okada M. Five-year longitudinal study of dental caries risk associated with Streptococcus mutans and Streptococcus sobrinus in individuals with intellectual disabilities. J Oral Sci. (2017) 59:39-46. doi: 10.2334/josnusd.16-0325

28. Okada M, Kawamura M, Oda Y, Yasuda R, Kojima T, Kurihara H. Caries prevalence associated with Streptococcus mutans and Streptococcus sobrinus in Japanese schoolchildren. Int J Paediatr Dent. (2012) 22:3428. doi: 10.1111/j.1365-263X.2011.01203.x

29. Scalioni F, Carrada C, Machado F, Devito K, Ribeiro LC, Cesar D, et al. Salivary density of Streptococcus mutans and Streptococcus sobrinus and dental caries in children and adolescents with down syndrome. J Appl Oral Sci. (2017) 25:250-7. doi: 10.1590/1678-7757-2016-0241

30. Singla D, Sharma A, Sachdev V, Chopra R. Distribution of Streptococcus mutans and Streptococcus sobrinus in dental plaque of indian pre-school children using PCR and SB-20M agar medium. J Clin Diagn Res. (2016) 10:ZC60-3. doi: 10.7860/JCDR/2016/19256.8909

31. Martinez-Martinez RE, Fujiwara T, Patino-Marin N, Hoshino T, Wilson M, Loyola-Rodriguez JP. Comparison of oral streptococci biofilm in cariesfree and caries-affected preschool Mexican children. Acta Odontol Latinoam. (2012) 25:27-32.

32. Babaeekhou L, Ghane M, Ezatzade F, Eftekhari Toroghi S. Streptococcus mutans and Streptococcus sobrinus distribution in the saliva and plaque of Iranian population: higher prevalence of S. mutans serotypes $f$ and $k$. Int $J$ Dent Hyg. (2021) 19:193-200. doi: 10.1111/idh.12485

33. Caufield PW, Schon CN, Saraithong P, Li Y, Argimon S. Oral Lactobacilli and dental caries: a model for niche adaptation in humans. J Dent Res. (2015) 94:110-8. doi: 10.1177/0022034515576052

34. Gao X, Jiang S, Koh D, Hsu CY. Salivary biomarkers for dental caries. Periodontol 2000. (2016) 70:128-41. doi: 10.1111/prd.12100

35. Karpinski TM, Szkaradkiewicz AK. Microbiology of dental caries. J Biol Earth Sci. (2013) 3:M21-4.

36. Badet C, Thebaud NB. Ecology of lactobacilli in the oral cavity: a review of literature. Open Microbiol J. (2008) 2:3848. doi: $10.2174 / 1874285800802010038$
37. Carlsson J, Grahnen H, Jonsson G. Lactobacilli and streptococci in the mouth of children. Caries Res. (1975) 9:333-9. doi: 10.1159/000260166

38. Kailis DG. Carnarvon studies. V. Oral lactobacillus estimations of 390 caucasian school children exposed to increased fluoride content of the town water supply in Carnarvon, Western Australia (August, 1965). Aust Dent J. (1970) 15:487-94. doi: 10.1111/j.1834-7819.1970.tb00952.x

39. Klock B, Krasse B. Microbial and salivary conditions in 9to 12-year-old children. Scand J Dent Res. (1977) 85:5663. doi: 10.1111/j.1600-0722.1977.tb00533.x

40. Kohler B, Bjarnason S, Finnbogason SY, Holbrook WP. Mutans streptococci, lactobacilli and caries experience in 12-year-old Icelandic urban children, 1984 and (1991). Commun Dent Oral Epidemiol. (1995) 23:65-8. doi: 10.1111/j.1600-0528.1995.tb00202.x

41. Loyola-Rodriguez JP, Martinez-Martinez RE, Flores-Ferreyra BI, PatinoMarin N, Alpuche-Solis AG, Reyes-Macias JF. Distribution of Streptococcus mutans and Streptococcus sobrinus in saliva of Mexican preschool cariesfree and caries-active children by microbial and molecular (PCR) assays. J Clin Pediatr Dent. (2008) 32:121-6. doi: 10.17796/jcpd.32.2.cm00062530v $856 r 4$

42. Okada M, Soda Y, Hayashi F, Doi T, Suzuki J, Miura K, et al. Longitudinal study of dental caries incidence associated with Streptococcus mutans and Streptococcus sobrinus in pre-school children. J Med Microbiol. (2005) 54:6615. doi: $10.1099 / \mathrm{jmm} \cdot 0.46069-0$

43. Damle SG. Competence and Transformation of oral Streptococcus sobrinus in dental caries. Contemp Clin Dent. (2018) 9:S1956. doi: $10.4103 /$ ccd.ccd_689_18

44. Domejean S, Zhan L, DenBesten PK, Stamper J, Boyce WT, Featherstone JD. Horizontal transmission of mutans streptococci in children. J Dent Res. (2010) 89:51-5. doi: 10.1177/0022034509353400

45. Klein MI, Florio FM, Pereira AC, Hofling JF, Goncalves RB. Longitudinal study of transmission, diversity, and stability of Streptococcus mutans and Streptococcus sobrinus genotypes in Brazilian nursery children. J Clin Microbiol. (2004) 42:4620-6. doi: 10.1128/JCM.42.10.4620-46 26.2004

46. Qin XR, Zhou Q, Qin M. Genotypic diversity and virulence traits of streptococcus sobrinus isolated from caries-free children and children suffering severe early childhood caries. Chin J Dent Res. (2013) 16:63-9.

47. Zhou Q, Qin X, Qin M, Ge L. Genotypic diversity of Streptococcus mutans and Streptococcus sobrinus in 3-4-year-old children with severe caries or without caries. Int J Paediatr Dent. (2011) 21:422-31. doi: 10.1111/j.1365-263X.2011.01145.x

48. Johansson I, Witkowska E, Kaveh B, Lif Holgerson P, Tanner AC. The microbiome in populations with a low and high prevalence of caries. J Dent Res. (2016) 95:80-6. doi: 10.1177/0022034515609554

49. Tiwari T, Jamieson L, Broughton J, Lawrence HP, Batliner TS, Arantes R, et al. Reducing indigenous oral health inequalities: a review from 5 nations. J Dent Res. (2018) 97:869-77. doi: 10.1177/0022034518763605

Conflict of Interest: The authors declare that the research was conducted in the absence of any commercial or financial relationships that could be construed as a potential conflict of interest.

Publisher's Note: All claims expressed in this article are solely those of the authors and do not necessarily represent those of their affiliated organizations, or those of the publisher, the editors and the reviewers. Any product that may be evaluated in this article, or claim that may be made by its manufacturer, is not guaranteed or endorsed by the publisher.

Copyright $\odot 2021$ Villhauer, Lynch, Postler, Dawson and Drake. This is an openaccess article distributed under the terms of the Creative Commons Attribution License (CC BY). The use, distribution or reproduction in other forums is permitted, provided the original author(s) and the copyright owner(s) are credited and that the original publication in this journal is cited, in accordance with accepted academic practice. No use, distribution or reproduction is permitted which does not comply with these terms. 